\title{
Is there an inherent limit to the efficacy of calcitonin gene-related peptide receptor antagonists in the acute treatment of migraine? A comment
}

\author{
Peer C. Tfelt-Hansen
}

Received: 24 August 2009/Accepted: 1 September 2009/Published online: 25 September 2009

(C) Springer-Verlag 2009

\begin{abstract}
Calcitonin gene-related peptide (CGRP) receptor antagonists are a new treatment principle in acute migraine attacks. Intravenous olcegepant $2.5 \mathrm{mg}$ resulted in $66 \%$ headache relief after $2 \mathrm{~h}$, whereas subcutaneous sumatriptan resulted in $81-92 \%$ headache relief after $2 \mathrm{~h}$. The intrinsic activity of a parenteral triptan, a $5 \mathrm{HT}_{1 \mathrm{~B} / 1 \mathrm{D}}$ receptor agonist, is thus higher than the maximum effect of the parenteral CGRP receptor antagonist olcegepant. For the orally bioavailable CGRP antagonist telcagepant $300 \mathrm{mg}$, the headache relief was only $55 \%$ in one phase III study. These results indicate that CGRP receptor antagonism results in success in the acute treatment of migraine in only a certain fraction of the patients.
\end{abstract}

\section{Introduction}

The involvement of calcitonin gene-related peptide (CGRG) in migraine is shown by the fact that CGRP infusion causes migraine without aura in migraineurs [1]. In addition, the two CGRP antagonists, olcegepant and telcagepant, are effective in the acute treatment of migraine [2-4]. A major advantage of CGRP antagonists compared with the triptans, is the lack, so far, of clinically important vascular adverse events [2-4].

The efficacy of oral drugs such as triptans and CGRP antagonists in the acute treatment of migraine most likely

\section{P. C. Tfelt-Hansen $(\square)$}

Danish Headache Centre, Glostrup Hospital,

Glostrup, Denmark

e-mail: ptha@glo.regionh.dk

P. C. Tfelt-Hansen

Department of Neurology, University of Copenhagen,

Glostrup, Denmark depends on several factors such as bioavailability [5], Tmax [5], lipophilicity and intrinsic activity/blocking efficacy. Triptans are $5-\mathrm{HT}_{1 \mathrm{~B} / 1 \mathrm{D}}$ receptor agonist and by increasing the parenteral dose of a triptan used in randomised clinical trials (RCTs) one can get an estimate of the intrinsic activity of the drug.

One cannot directly compare the results of a receptor agonist such as a triptan with that of a receptor antagonist such as the CGRP antagonists, olcegepant and telcagepant. Whereas the maximum effect of an agonist depends on its intrinsic activity, the efficacy of the receptor antagonist apart from its blocking potency also depends on the involvement of the biological agonist it is presumed to block, in the migraine process. If the biological agonist is not the only factor involved in the migraine process, one cannot expect the antagonist to cure all cases.

\section{Review of some randomised clinical trials with triptans and CGRP antagonists}

Intrinsic activity of triptans in acute migraine treatment

The maximum effect of a triptan has been shown for subcutaneous naratriptan $10 \mathrm{mg}$ for which $88 \%$ pain-free response after $2 \mathrm{~h}$ was found in one RCT [6, 7]. This very high pain-free response comes with a penalty of $71 \%$ adverse events (AEs) [6]. For subcutaneous sumatriptan $6 \mathrm{mg}$, the pain-free response was $55 \%$ and the AEs were $53 \%[6,7]$. In contrast, sumatriptan $6 \mathrm{mg}(81 \%, 86 \%, 89 \%$, $92 \%[6,8,9])$ and naratriptan $10 \mathrm{mg}(91 \%)$ resulted in quite similar headache relief (a decrease from moderate or severe to none or mild) after $2 \mathrm{~h}$ [6]. Headache relief has been the primary efficacy measure in many RCTs [8-10] 
and is still widely used [2-4] and will therefore be used in the following.

For the most effective triptan form used clinically, subcutaneous sumatriptan $6 \mathrm{mg}$, the therapeutic gain (TG) (percentage response with active drug minus response with placebo) for headache relief is $51 \%$ (95\% CI, 48-53\%) after $1 \mathrm{~h}$ [10]. For oral sumatriptan $100 \mathrm{mg}$ the TG is $33 \%$ (95\% CI, 31-35\%) after $2 \mathrm{~h}[10]$

Effect of CGRP receptor antagonists in acute migraine treatment

In the olcegepant RCT from 2004 the headache relief for $2.5 \mathrm{mg}$ olcegepant, a very potent calcitonin gene-related peptide (CGRP) antagonist [11, 12], intravenously was $66 \%$ after $2 \mathrm{~h}$ but only $46 \%$ after $1 \mathrm{~h}$, [2]. These response rates and Fig. 1 illustrate, for an intravenous drug, the rather slow onset of action of olcegepant. The corresponding TG was 39\% (2 h) and 32\% (1 h), respectively [2].

In the case of olcegepant it has been estimated that the dose used, $2.5 \mathrm{mg}$, is about 1,000 times the concentration needed for peripheral blockade of CGRP [13]. There should therefore most likely, even in theoretical deep departments such as beyond the BBB, be enough CGRP blocker present to block the effect of CGRP. This is supported by the results in cats [14]. Olcegepant caused a dose-dependent inhibition of superior sinus sagittalisevoked activity in trigeminal nucleus caudalis with an ED50 of $31 \mu \mathrm{g} / \mathrm{kg}$ [14]. This corresponds to $2.1 \mathrm{mg} / 70 \mathrm{~kg}$ and is thus near the chosen optimal therapeutic dose of olcegepant $2.5 \mathrm{mg}$ intravenously [2].

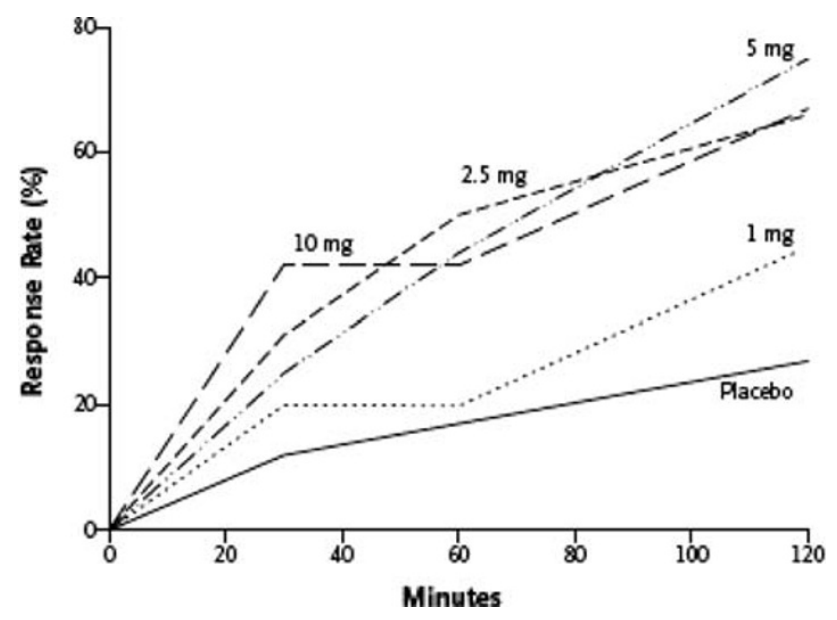

Fig. 1 Rates of headache relief after $10 \mathrm{~min}$ intravenous infusion of olcegepant $1-10 \mathrm{mg}$ or placebo according to the time after start of the infusion. From [2] with permission
Furthermore, in a human study olcegepant $2.5 \mathrm{mg}$ completely blocked the majority of the effects of h- $\alpha \mathrm{CGRP}$ infused in a high dose of $1.5 \mu \mathrm{g} / \mathrm{min}$ [15]. Thus, CGRP receptor blockade in the migraine study [2] must most likely have been nearly complete. It should be noted that $10 \mathrm{mg}$ olcagepant did not result in more patients with headache relief $(68 \%)$ than after $2.5 \mathrm{mg}(66 \%)$ [2]. Thus, the effect of intravenous olcegepant $2.5 \mathrm{mg}$ is most likely near the maximal effect one can expect of a CGRP antagonist in migraine.

The first orally bioavailable CGRP receptor antagonist, telcagepant, has been studied in two RCTs [3, 4]. After a dose-defining RCT [3] telcagepant $300 \mathrm{mg}$ was chosen as the optimal dose in a phase III RCT [4].Clinically the effect of telcagepant in the phase III study [4] was not that impressive [16]. Thus, the $2 \mathrm{~h}$ pain freedom was $27 \%$ for telcagepant $300 \mathrm{mg}$ versus $10 \%$ for placebo and headache relief was 55 and $28 \%$, respectively [4]. The TG for telcagepant for headache relief was thus $27 \%$ (95\% CI, 20$34 \%$ ) apparently similar to the TG for oral sumatriptan 100, 33\% (95\% CI, 31-35\%), but more data on telcegepant are needed.

How high a dose is telcagepant $300 \mathrm{mg}$, the absolute headache relief was $67 \%$ for $300 \mathrm{mg}, 400 \mathrm{mg}$ and $68 \%$ $600 \mathrm{mg}$ in a relatively small dose-defining RCT with a high placebo response of $46 \%$ [3]. Thus, doubling the dose from 300 to $600 \mathrm{mg}$ did not increase efficacy and the efficacy of the $300 \mathrm{mg}$ dose is probably near the maximal effect of telcagepant.

\section{Conclusion}

When given intravenously, the potent CGRP receptor antagonist olcegepant 2.5 most likely results in a maximal effect in the treatment of acute migraine [2]. Despite the optimal dosage form, the headache relief was $46 \%$ after $1 \mathrm{~h}$ and $66 \%$ after $2 \mathrm{~h}$, considerably less than the $70 \%$ after $1 \mathrm{~h}$ and $81-92 \%$ after $2 \mathrm{~h}$ for subcutaneous sumatriptan $6 \mathrm{mg}$ $[6,8,9]$. The intrinsic activity of the most potent clinically used triptan, subcutaneous sumatriptan $6 \mathrm{mg}$, is thus higher than the maximal effect of the intravenously used CGRP antagonist, olcagepant $2.5 \mathrm{mg}$.

This indicates that there is most likely an inherent limit to the response one can expect from CGRP receptor antagonist, such as olcegepant and telcagepant, in the acute treatment of migraineurs as a group.

One possible hypothetical explanation for this is that CGRP is not involved in the final steps of the pathophysiological process of migraine. Instead these final steps in the pathophysiological process of migraine could involve nitric oxide [17]. 
Conflict of interest None.

\section{References}

1. Lassen LH, Haderslev PA, Jacobsen VB, Iversen HK, Sperling B, Olesen J (2002) CGRP may play a causative role in migraine. Cephalalgia 22:54-61

2. Olesen J, Diener HC, Husstedt IW, Goadsby PJ, Hall D, Meier U, BIBN4096BS Clinical Proof of Concept Study Group et al (2004) Calcitonin gene-related peptide receptor antagonist olcegepam for the acute treatment of migraine. N Eng J Med 350:1104-1110

3. Ho TW, Mannix LK, Fan X, Assaid C, Furtek C, Jones CJ et al (2008) Randomized controlled trial of an oral CGRP receptor antagonist, MK-0974, in the acute treatment of migraine. Neurology 70:1304-1312

4. Ho TW, Ferrari MD, Dodick DW, Galet V, Kost J, Fan X et al (2008) Efficacy and tolerability of MK-0974 (telcagepant), a new oral antagonist of calcitonin gene-related peptide receptor, compared with zolmitriptan for acute migraine: a randomised, placebo-controlled, parallel-treatment trial. Lancet 372:2115-2123

5. Tfelt-Hansen P (2007) Parenteral versus oral sumatriptan and naratriptan: plasma levels and efficacy in migraine. A comment. J Headache Pain 8:273-276

6. Dahlöf C, Hogenhuis L, Olesen J, Petit H, Ribbat J, Schoenen J et al (1998) Early clinical experience with subcutaneous naratriptan in the acute treatment of migraine: a dose-ringing study. Eur J Neurol 5:469-477

7. Tfelt-Hansen $P$ (2008) Maximum effect of triptans in migraine? A comment. Cephalalgia 26:767-768

8. Cady RK, Wendt JK, Kirchner JR, Sargent JD, Rothrock JF, Skaggs H (1991) Treatment of acute treatment with subcutaneous sumatriptan. JAMA 265:2831-2835

9. Subcutaneous Sumatriptan International Study Group (1991) Treatment of migraine attacks with sumatriptan. N Eng J Med 325:316-321
10. Tfelt-Hansen P, De Vries P, Saxena PR (2000) Triptans in migraine. A comparative review of pharmacology, pharmacokinetics and efficacy. Drugs 60:1259-1287

11. Rudolf K, Eberlein W, Engel W, Pieper H, Entzeroth M, Hallermayer G, Doods H (2005) Development of human generelated peptide (CGRP) receptors antagonists. 1. Potent and selective small molecule CGRP antagonists. 1-[ $N$-[3, 5-dibromo$N[[4-(3,4-d i h y d r o-2(1 \mathrm{H})$-oxoquinazolin-3-yl)-1-piperidinyl $]$ carbonyl]-D-tyrosyl]-I-lysyl]-4-4-(4-pyridinyl)piperazine: the first CGRP antagonist for clinical trials in acute migraine. J Med Chem 48:5921-5931

12. Doods H, Hallermayer G, Wu D, Entzeroth M, Rudolf K, Engel W et al (2000) Pharmacological profile of BIBN4096BS, the first small molecule CGRP antagonist. $\mathrm{Br} \mathrm{J}$ Pharmacol 129:420-423

13. Edvinsson L, Nielson E, Jansen-Olesen I (2007) Inhibitory effect of BIBN4096BS, CGRP8-37, a CGRP antibody and a RNA-Spiegelmer on CGRP induced vasodilatation in the perfused and non-perfused rat middle cerebral artery. Br J Pharmacol 150:633-640

14. Storer RJ, Akerman S, Goadsby PJ (2004) Calcitonin gene-related peptide (CGRP) modulates nociceptive trigeminovascular transmission in the cats. Br J Pharmacol 142:1171-1181

15. Petersen KA, Lassen LH, Birk S, Lesko L, Olesen J (2005) BIBN4096BS antagonizes human $\alpha$-calcitonin gene related peptide-induced headache and extracerebral artery dilatation. Clin Pharmacol Ther 77:202-213

16. Tfelt-Hansen P (2009) Migraine and telcagepant. Lancet 373:1003

17. Olesen J, Iversen HK, Thomsen LL (1993) Nitric oxide supersensitivity. A possible molecular mechanism of migraine pain. Neuroreport 4:1027-1030 